\title{
MONTHLY MEAN PRESSURE RECONSTRUCTIONS FOR EUROPE FOR THE 1780-1995 PERIOD
}

\author{
P.D. JONES ${ }^{a}, *$ T.D. DAVIES ${ }^{a}$, D.H. LISTER ${ }^{a}$, V. SLONOSKY ${ }^{a}$, T. JÓNSSON ${ }^{b}$, L. BÄRRING ${ }^{c}$, P. JÖNSSON $^{c}$, \\ P. MAHERAS ${ }^{\mathrm{d}}$, F. KOLYVA-MACHERA ${ }^{\mathrm{d}}$, M. BARRIENDOS ${ }^{\mathrm{e}}, \mathrm{J}^{\text {. MARTIN-VIDE }}$ MA $^{\mathrm{e}}$ R. RODRIGUEZ ${ }^{\mathrm{e}}$,

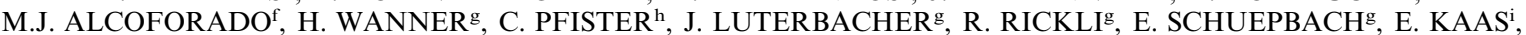 \\ T. SCHMITH ${ }^{\mathrm{i}}$, J. JACOBEIT ${ }^{\mathrm{j}}$ and C. BECK ${ }^{\mathrm{j}}$ \\ ${ }^{a}$ Climatic Research Unit, University of East Anglia, Norwich NR4 7TJ, UK \\ ${ }^{\mathrm{b}}$ Icelandic Meteorological Service (Vedurstofa Islands), Reykjavik IS-150, Iceland \\ ${ }^{c}$ Department of Physical Geography, Lund University, Lund S-22362, Sweden \\ d Department of Meteorology and Climatology, University of Thessaloniki, Thessaloniki 54006, Greece \\ e Departmento de Geografia Fisica, Universitat de Barcelona, Barcelona 08028, Spain \\ ${ }^{\mathrm{f}}$ Departmento de Geografia, Universidade de Lisboa, Lisbon 1699 Codex, Portugal \\ ${ }^{\mathrm{g}}$ Institute of Geography, University of Berne, Berne 3012, Switzerland \\ ${ }^{\mathrm{h}}$ Historisches Institut, University of Berne, Berne 3012, Switzerland \\ ${ }^{i}$ Danish Meteorological Institute Lyngbyvej 100, Copenhagen 2100, Denmark \\ ${ }^{\mathrm{j}}$ Geographisches Institut, Julius-Maximillians-Universität Würzburg, Würzburg D-97070, Germany
}

\begin{abstract}
Monthly grid-point pressure data are reconstructed from station records of pressure for Europe since 1780. The region encompasses $35-70^{\circ} \mathrm{N}$ to $30^{\circ} \mathrm{W}-40^{\circ} \mathrm{E}$. The reconstructions are based on a principal components regression technique, which relates surface pressure patterns to those of the station pressure data. The relationships are derived over a calibration period (1936-1995) and the results tested with independent data (the verification period, 1881-1935). The reconstructions are of excellent quality, although this is slightly lower for regions with poor station coverage in the early years, particularly during the summer months.

The reconstructions are compared with other monthly mean pressure maps produced by Lamb and Johnson (1966) for the years $1780-1872$ and by Kington $(1980,1988)$ for $1781-1785$. Both of these map series show systematic biases relative to the present reconstructions.
\end{abstract}

KEY WORDS: pressure; Europe; principal components; regression; reconstruction

\section{INTRODUCTION}

Studies of atmospheric circulation over the European region are generally confined to the period since the late 19th century. This limitation is not due to a lack of station data, but to the fact that gridded monthly mean sea level pressure (MSLP) data are only available since the late 19th century (see Section 2.1 for discussion of sources). The barometer was invented in the early 17th century, however, and long and well-known MSLP and station-level series have been developed for several locations in Europe. For this region, therefore, there should be much longer gridded series than elsewhere in the world.

Early attempts to utilise this wealth of MSLP data were concentrated in two areas: the hand-drawn construction of (a) monthly charts for January and July since 1750 by Lamb and Johnson (1966); and (b) daily charts for selected periods, particularly the 1780s (Kington, 1980, 1988). The advent of high-speed computers, however, has negated the need to laboriously plot all the data onto charts. Instead, effort can be concentrated on homogeneity testing and adjustment of the station MSLP time series and on the accuracy of the resulting pressure maps.

* Correspondence to: Climatic Research Unit, University of East Anglia, Norwich NR4 7TJ, UK. 
Jones et al. (1987) used a principal components regression technique to produce monthly gridded MSLP data by relating the principal component patterns of gridded pressure data to station pressure data. The technique produced monthly maps back to 1780 for Europe, and back to 1858 for North America. The main advantages of this technique over earlier methods are the ease of the approach, enabling additional stations to be incorporated when their data are located and, more importantly, the quality of the resulting monthly pressure maps can be objectively assessed with statistical techniques.

Since 1987, considerably more sources of early MSLP data have been located in Europe. This paper uses these data to present improved reconstructions for the 1780-1995 period. Additional data in the new work has dramatically improved the reconstructed MSLP maps during much of the 1780-1880 period. The new work uses 51 station series compared to 32 in 1987, ten of which extend back to 1780, compared with only four in the earlier study.

The work is part of a larger European Community funded research project, ADVICE (Annual-toDecadal Variability In Climate over Europe). There are five main aims to this project as follows.

1. Reconstruction of monthly MSLP charts for the 1780-1880 period (work reported here).

2. Reconstruction of monthly MSLP charts for the $1675-1715$ period.

3. Reconstruction of daily weather charts for selected anomalous periods over 1780-1860 (defined from 1).

4. Analyses of the reconstructed MSLP grids to establish whether significant changes in atmospheric circulation have occurred since 1780 (Beck and Jacobeit, 1997Schmutz and Wanner, 'Low-frequency variability of atmospheric circulation over Europe between 1785 and 1994', manuscript in preparation).

5. Modelling studies of the importance of North Atlantic sea-surface temperature and sea-ice conditions to European circulation patterns over the 1675-1995 period.

This paper is organised into five parts. Section 2 discusses the data sources used with particular regard to the homogeneity of the individual station time series. The reconstruction method is the same as that used by Jones et al. (1987) and is briefly outlined in Section 3. The quality of the reconstructions is assessed in Section 4, and comparisons with earlier work (Lamb and Johnson, 1966; Jones et al., 1987; Kington, 1988) are addressed in Section 5. Some conclusions and suggestions for further improvements are made in the final section.

\section{PRESSURE DATA AND HOMOGENEITY}

\subsection{Gridded data}

Grid-point values of northern hemisphere MSLP data are available from the late 19th century. Two versions of the dataset exist: (a) the United Kingdom Meteorological Office (UKMO) version, extending back to 1873 on a $5^{\circ}$ latitude by $10^{\circ}$ longitude grid from $15^{\circ} \mathrm{N}$ polewards (see Jones, 1987 for source details); and (b) the National Center for Atmospheric Research (NCAR) version, beginning in 1899, on a $5^{\circ}$ latitude by $5^{\circ}$ longitude grid (see Trenberth and Paolino, 1980 for source details). For some of the overlapping periods since 1899 the sources are the same, but differing corrections for the numerous problems related to sparse data regions, elevation and observation time effects means that there are significant differences between the two versions. The only comparison of the two datasets undertaken (Williams and van Loon, 1976) indicated that the datasets are most similar between 1899 and 1939, but since 1940 different sources and corrections have produced significant differences. The largest differences are in the summer season (June-August), particularly over the Himalayas and the Rocky Mountains.

Both Trenberth and Paolino (1980) and Jones (1987) have compared station time series with the gridded data. Many of the grid-point time series reveal discontinuities, with inhomogeneities related to changes in sources, improvements in data availability and changes to elevation corrections. For the European region, both sets of charts are considered reliable, although homogeneity problems may be 
expected in the southeast of the region over Asia Minor and the Middle East. This region was noted as unreliable by Williams and van Loon (1976) and the results were consistently poor there in the earlier study of Jones et al. (1987).

In terms of quality, there is little to choose between the two gridded datasets, but because the UKMO dataset extends back to 1873 for the North Atlantic/European sector of the northern hemisphere $\left(90^{\circ} \mathrm{W}-90^{\circ} \mathrm{E}\right)$, this dataset was chosen. A grid of 60 points was selected with complete data for each month from 1873 to 1995 . The grid-points extend from $70^{\circ}$ to $35^{\circ} \mathrm{N}$ and from $30^{\circ} \mathrm{W}$ to $40^{\circ} \mathrm{E}$ (Figure 1). Jones et al. (1987) remarked on the poorer quality of the first 8 years of data (1873-1880), so only the period from 1881 to 1995 is used here to develop the reconstructions. The version used in this paper includes some recent further corrections documented by Basnett and Parker (1997), although they are relatively small for this region.

Two other sets of gridded data are available in digital form: (a) the January and July charts since 1750 developed by Lamb and Johnson (1966); and (b) data digitised from the daily charts produced for the 1781-1785 period by Kington $(1980,1988)$. The quality of both datasets has been addressed in Jones et al. (1987). Further comments regarding the quality of these data will be made in Section 5 when they are compared with the reconstructions produced here.

\subsection{Station data}

Station time series of MSLP and station-level pressure were collected for 51 sites across central Europe. This represents an increase of 19 sites over Jones et al. (1987), but more importantly, much longer records were found for a number of sites. As a consequence of the shortcomings noted in the 1987 study, emphasis was placed on the peripheral areas of Europe, with searches concentrated in the Mediterranean, Iceland and the extreme northern and eastern regions of Europe.

The locations of all 51 sites are shown in Figure 2 and Table I. The sources of all the time series, almost all of which are complete, are listed in ADVICE (1998). Some of the sites were merely updated from the

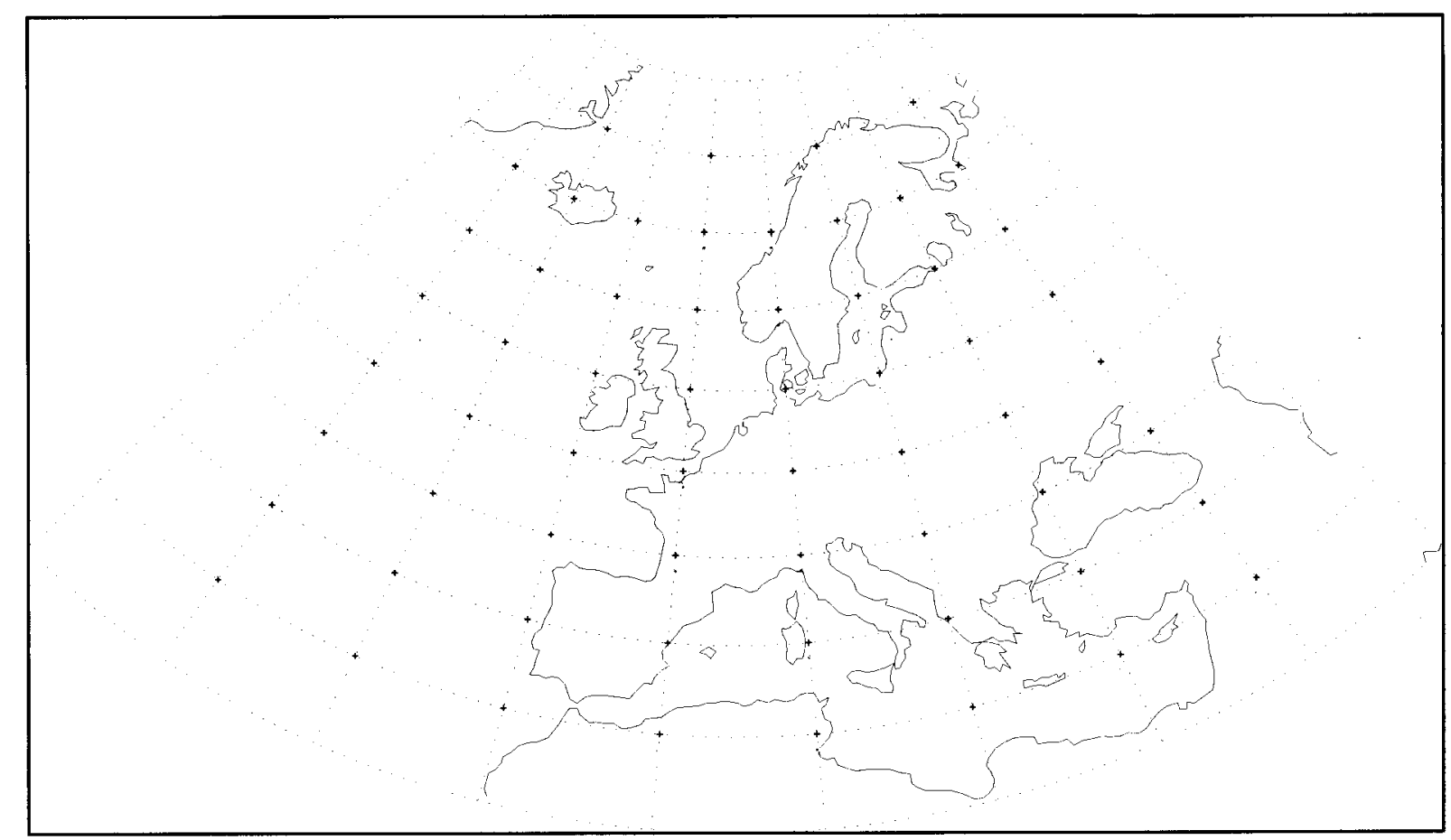

Figure 1. The 60-point grid over Europe 


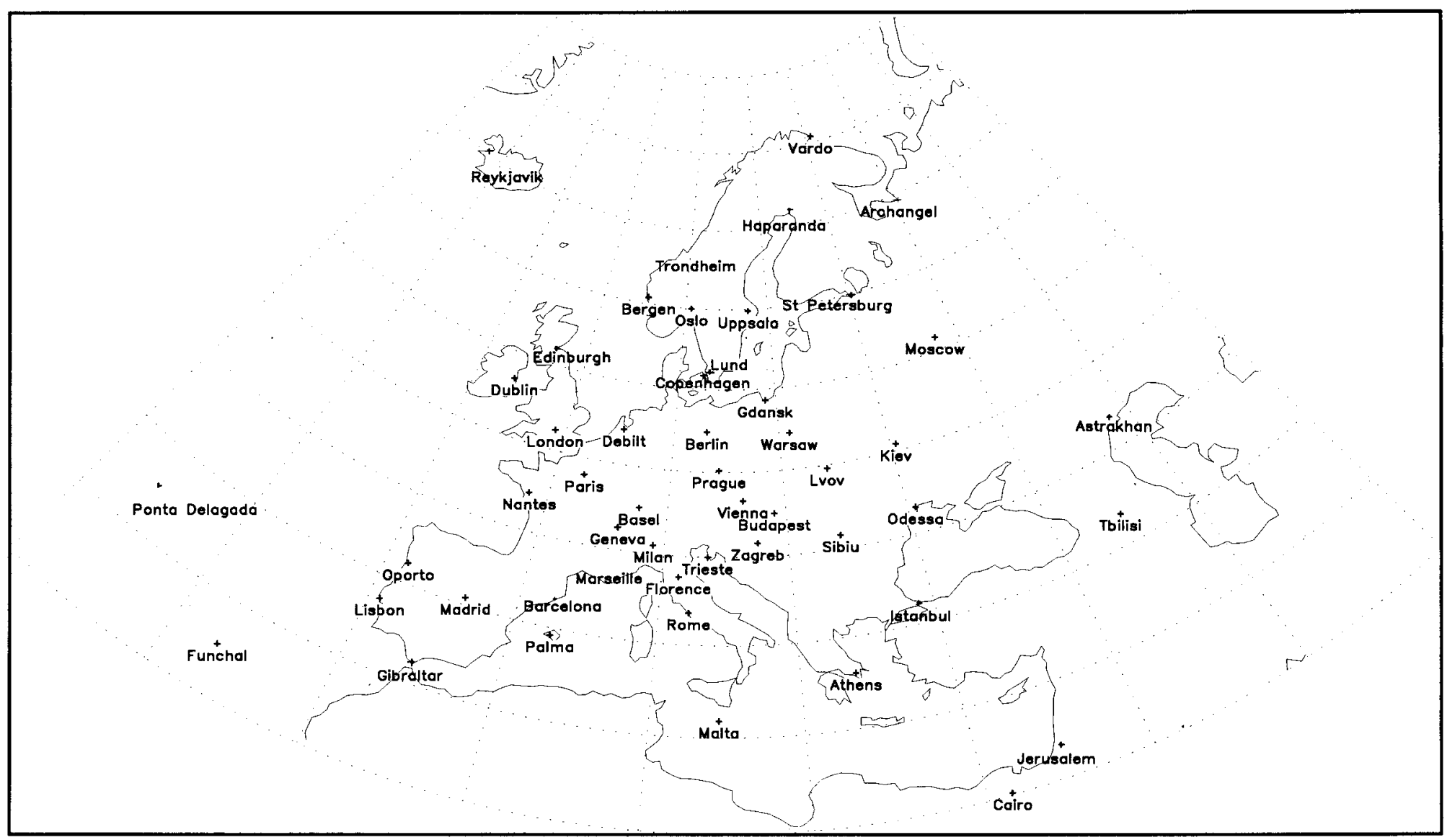

Figure 2. The locations of 51 sites for which station pressure series have been developed. The lengths of each record are given in Table I 
Table I. The 51 sites of pressure data

\begin{tabular}{|c|c|c|c|}
\hline No. & Station & First year & Reconstruction network \\
\hline 1 & Basel & 1755 & $\mathrm{~L}$ \\
\hline 2 & Milan & 1763 & $\mathrm{~L}$ \\
\hline 3 & Paris & 1764 & $\mathrm{~L}$ \\
\hline 4 & Geneva & 1768 & $\mathrm{~L}$ \\
\hline 5 & Trondheim & 1768 & $\mathrm{~L}$ \\
\hline 6 & Edinburgh & 1770 & $\mathrm{~L}$ \\
\hline 7 & London & 1774 & $\mathrm{~L}$ \\
\hline 8 & Vienna & 1775 & $\mathrm{~L}$ \\
\hline 9 & Barcelona & 1780 & $\mathrm{~L}$ \\
\hline 10 & Lund & 1780 & $\mathrm{~L}$ \\
\hline 11 & Madrid & 1786 & $\mathrm{~K}$ \\
\hline 12 & Prague & 1789 & $\mathrm{~K}$ \\
\hline 13 & Gdansk & 1807 & $\mathrm{~J}$ \\
\hline 14 & Budapest & 1809 & $\mathrm{~J}$ \\
\hline 15 & Florence & 1814 & I \\
\hline 16 & Bergen & 1816 & I \\
\hline 17 & Oslo & 1816 & I \\
\hline 18 & Gibraltar & 1821 & $\mathrm{H}$ \\
\hline 19 & Reykjavik & 1821 & $\mathrm{H}$ \\
\hline 20 & St. Petersburg & 1822 & $\mathrm{H}$ \\
\hline 21 & Dublin & 1831 & G \\
\hline 22 & Warsaw & 1836 & G \\
\hline 23 & Moscow & 1838 & G \\
\hline 24 & Trieste & 1841 & $\mathrm{~F}$ \\
\hline 25 & Copenhagen & 1842 & $\mathrm{~F}$ \\
\hline 26 & Odessa & 1842 & $\mathrm{~F}$ \\
\hline 27 & Tbilisi & 1844 & $\mathrm{~F}$ \\
\hline 28 & De Bilt & 1849 & $\mathrm{E}$ \\
\hline 29 & Archangel & 1851 & $\mathrm{E}$ \\
\hline 30 & Berlin & 1851 & $\mathrm{E}$ \\
\hline 31 & Lvov & 1851 & $\mathrm{E}$ \\
\hline 32 & Marseille & 1851 & E \\
\hline 33 & Nantes & 1851 & $\mathrm{E}$ \\
\hline 34 & Rome & 1851 & E \\
\hline 35 & Sibiu & 1851 & $\mathrm{E}$ \\
\hline 36 & Malta & 1852 & $\mathrm{D}$ \\
\hline 37 & Lisbon & 1855 & $\mathrm{D}$ \\
\hline 38 & Istanbul & 1856 & $\mathrm{D}$ \\
\hline 39 & Athens & 1858 & $\mathrm{D}$ \\
\hline 40 & Haparanda & 1860 & $\mathrm{C}$ \\
\hline 41 & Uppsala & 1860 & $\mathrm{C}$ \\
\hline 42 & Jerusalem & 1861 & $\mathrm{C}$ \\
\hline 43 & Vardo & 1861 & $\mathrm{C}$ \\
\hline 44 & Zagreb & 1862 & $\mathrm{~B}$ \\
\hline 45 & Oporto & 1863 & B \\
\hline 46 & Funchal & 1865 & B \\
\hline 47 & Ponta Delgada & 1865 & B \\
\hline 48 & Palma & 1866 & A \\
\hline 49 & Astrakhan & 1868 & A \\
\hline 50 & Cairo & 1869 & A \\
\hline 51 & Kiev & 1871 & A \\
\hline
\end{tabular}

earlier work (Jones et al., 1987) so these source details are given in the 1987 publication. A few were developed specifically for this project and have been documented (e.g. Barcelona (Rodriguez et al., 'The long pressure series of Barcelona (Spain), daily reconstruction and monthly homogenization', manuscript 
submitted to the International Journal of Climatology) and Lund (Bärring et al., 'The Lund pressure record of meteorological instrumental observations: monthly pressure 1780-1997', manuscript submitted to the International Journal of Climatology)). The basic source of most of the series are World Weather Records, Monthly Climatic Data for the World and Reseau Mondial, although there are a number of important compilations of early pressure data, particularly for the 19th century, namely Hann (1887), de Tillo (1890) and Gorczynski (1917). It would have been possible to use many more stations in western and central Europe from about 1860 onwards, but we considered the density in these regions was adequate after this time.

After locating the station data for the 19 new station series and extending and/or updating the original 32 series, we had the difficult task of assessing each station record for homogeneity. It is rare for any station to be completely homogeneous over its entire record length, as site changes (both position and elevation), observation time changes and changes in procedures affect the measurements (e.g. changes in the value of 'standard' gravity). Of greatest importance is the fact that many of the early records (particularly pre-1850) have not been corrected to sea level or had gravity corrections applied. With the majority of the station records composed of data from more than one source, it is vitally important to assess the long-term homogeneity of each series.

The homogeneity of each station was considered in a two-stage process. In Stage 1, referred to as the 'grid check' comparison, a series for the station was developed from the $5^{\circ} \times 10^{\circ}$ grid-point dataset (see Section 2.1) for the years 1881-1995. A simple distance weighted scheme was used to estimate the station's value from the four surrounding grid-point values. The purpose of this stage was twofold. First, it easily identified erroneous values in the station time series and allowed missing values to be objectively estimated. Second, a plot of the annual mean pressure difference between the station and the grid-estimated series often revealed abrupt jumps where it was presumed the station series required adjustments. Monthly adjustment factors were estimated based on the differences.

In Stage 2 of the procedure, referred to as the 'inter-station' comparison, neighbouring stations are compared over their entire record lengths by plotting the pressure difference series between two stations on an annual basis. All difference plots were inspected visually and tested using objective techniques (e.g. Alexandersson, 1986) to determine possible change points (Slonosky et al., 'Homogenization technique for European monthly mean surface pressure time series', manuscript submitted to J. Clim.). Subjective judgements based on experience were then made to determine which stations and for which periods adjustments were needed.

Adjustment values determined from both stages of the procedure are listed in ADVICE (1998). The procedure is necessarily somewhat ad hoc and subjective, since even supposedly objective homogeneity assessment techniques require a considerable amount of subjective interpretation. Adjustment values were determined on a monthly basis even though the change points were determined on an annual basis. For a few stations, the small Stage 1 adjustments $( \pm 1.5 \mathrm{hPa})$ were sometimes reversed during Stage 2 .

\section{RECONSTRUCTION METHOD}

The reconstruction technique is based on principal components regression (see Jones et al., 1987 for the full mathematical details). Both the grid-point (60) and station network (51) are separately transformed into principal components (PCs) using the correlation matrix. The PCs are orthogonal linear combinations of the original data, each representing decreasing amounts of the original total variance. In most cases, a high proportion of the variance can be explained by relatively few PCs, with the remaining high order components representing unwanted noise. There are no definitive rules to decide how many components to retain. Preisendorfer et al. (1981) discuss the numerous methods that have been proposed. In this analysis, we retained enough PCs to explain $80 \%$ of the grid-point and $90 \%$ of the station variance. Different thresholds were used because it is believed the regular grid would produce more coherent patterns than the irregularly located station data. It was important to keep as much variance as possible from remote stations in the station PCs. The threshold percentages are the same as those used in Jones et al. (1987). 
Each of the retained grid-point PCs is then regressed in turn against all the retained PCs of the stations. Because of orthogonality, the procedure is very simple and stepwise regression techniques are unnecessary. Station PCs that explain little variance can be eliminated at this stage. Again there are no universally accepted rules for this, and we chose to ignore regression weights whose $t$-values were $<1$.

It is now a simple case to transform the whole analysis back to linear equations relating the pressure at each grid-point in terms of all the station data. Since the station network changes significantly over the 1780-1872 period, we developed 12 series of equations for the different networks applicable to progressively earlier starting dates (Table I). As circulation patterns vary during the year, separate equations were developed for each month, giving a total of 144 regression equations. The regression-based nature of the procedure means that it is vital to retain some independent data to assess the performance of the equations outside of the fitting period. With the available data covering the 1881-1995 period, we chose a calibration period of 1936-1995, verifying the results over 1881-1935.

The technique has been used widely in paleoclimatic reconstruction and been compared to Canonical Regression (CR), another technique for relating two matrices of data to each other by Cook et al. (1994). This study showed that there was little difference between CR and the Orthogonal Spatial Regression (OSR) used here, the differences becoming larger only when the relationships between the two matrices are weak. In our reconstruction examples, the explained variances are considerably higher than any paleoclimatic examples using proxy rather than instrumental data for the predictor dataset (cf. Jones et al., 1987 with the results given by Cook et al., 1994).
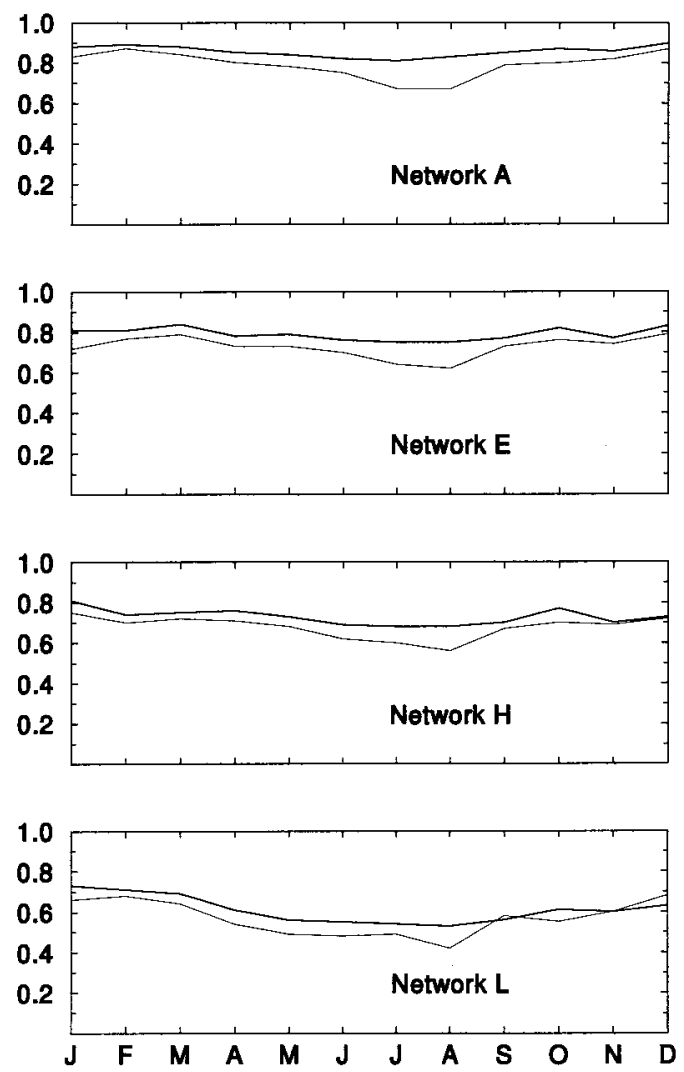

Figure 3. Overall performance (average explained variances) across the entire grid for four of the 12 networks (A, E, H and L). The thicker (upper) line is the calibration period and the thinner (lower) line the verification period 


\section{RESULTS AND ASSESSMENT}

Twelve sets of regression equations were developed, based on the calibration period from 1936 to 1995. The performance of the equations can be assessed in a number of ways, placing greatest emphasis on the results from the verification period from 1881 to 1935 as follows.

1. Overall model performance. This is the average explained variance across the whole 60 grid-point region, calculated over both the calibration and verification periods on a month-by-month basis for each of the 12 networks.

2. Spatial model performance. Maps of the explained variances over the calibration and verification periods for each month and a network showing which parts of the grid perform best.

3. Spatial correlation analysis. Instead of comparing the reconstructed and observed time series at each grid-point separately, the model performance can be assessed for each reconstructed map or time slice with the observed data.

\subsection{Overall model performance}

Figure 3 shows the overall performance of four of the 12 networks (A, E, H and L). These four networks were chosen since they incorporate the greatest changes in station numbers and location between the networks. The overall performance is the average of all the explained variances of the 60 grid-points, the value that has been optimised in the regression analysis. The best guide to model performance is this parameter calculated for the verification period. All models give a poorer performance during the summer months, with reductions from 90 to $81 \%$ for the best grid (A) compared to winter for the calibration period and from 73 to $53 \%$ for the poorest grid (L). Over the verification period, the explained variance is generally reduced by between 5 and 10\%. Compared to the earlier results in Jones et al. (1987), the new analyses show the greatest improvements in summer, particularly during the verification period.

\subsection{Spatial model performance}

Here the reconstructed and observed time series are compared for each grid-point. The results are shown in map form for the four mid-season months of January, April, July and October in Figures 4-7 for networks A, E, H and L, respectively. Generally, the best month is January, although for some networks it can be December or February. Conversely, July is usually the poorest month, although for some networks June and August are the poorest months.

All 16 maps have very similar features, with the central grid-points calibrating and verifying above $90 \%$. The poorer results in summer and in the verification period arise from the fact that the results around the periphery of the grid are worse in summer than in winter. In the earliest grids, verification contours bear some resemblance to concentric circles with tighter contours, hence greater reduction of variance explained, during July compared to January. As circulation anomalies are more structured in winter than in summer, there is a greater potential for estimating grid-points further away from the stations during the winter season.

The starting dates of a number of the records can be seen in many of the Figures. Network H, which is the first with the Icelandic station at Reykjavik, clearly performs better than network L over the northwest of the grid, particularly in July. Network E shows the improvement in the northeast when the Archangel record begins. Even for network A, the best network, the variance explained drops to values below $50 \%$ over the southeast and the central Mid-Atlantic, especially during the summer months. Reconstruction in the Azores region before the Ponta Delgada record begins will always be relatively poor outside the winter months, when there is greater correlation with the Iberian stations.

\subsection{Spatial correlation analysis}

Instead of comparing each reconstructed grid-point time series in isolation, another means of analysing the results is to compare the reconstructed and observed data over the whole area of analysis for each month separately. This can be carried out for both the calibration and verification periods by calculating spatial correlation coefficients between the data at all 60 grid-points (Briffa et al., 1986). This method, however, can give misleading results if it is applied to actual pressure values. Artificially high correlations 
verification $(R * R)$ January set $A$

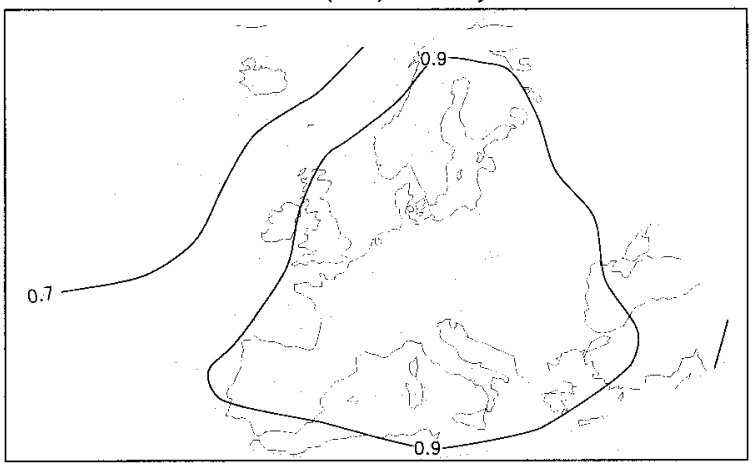

verification $(R * R)$ January set $H$

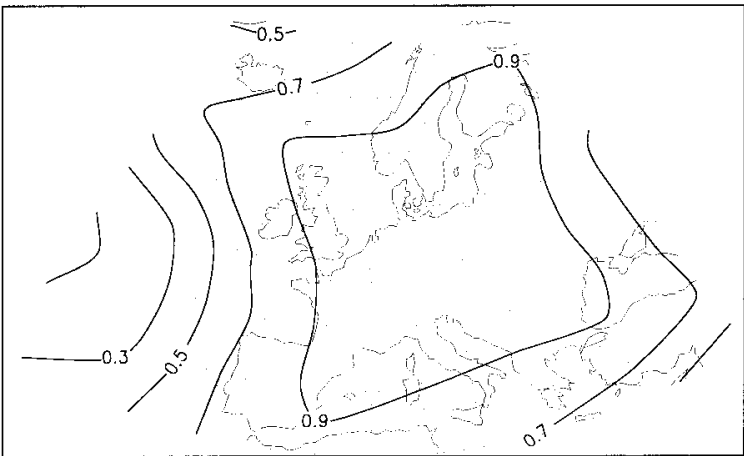

verification $(R * R)$ January set $E$

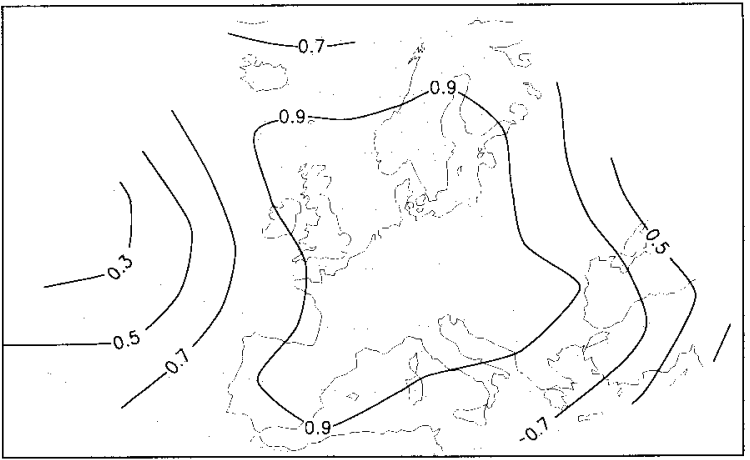

verification $(R * R)$ January set $L$

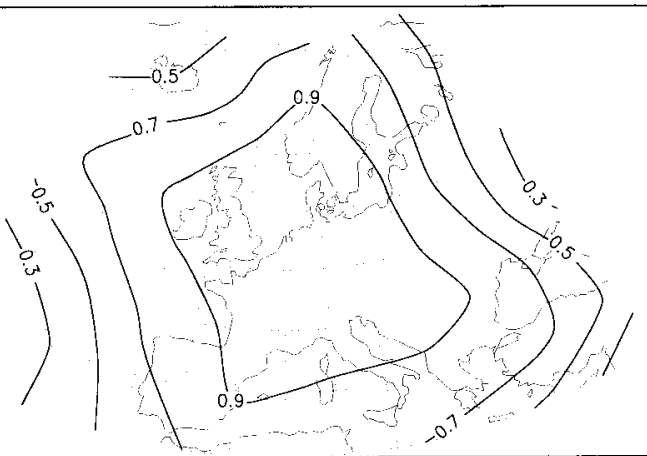

Figure 4. Spatial model performance for January for networks A, E, H and L

verification $(R * R)$ April set $A$

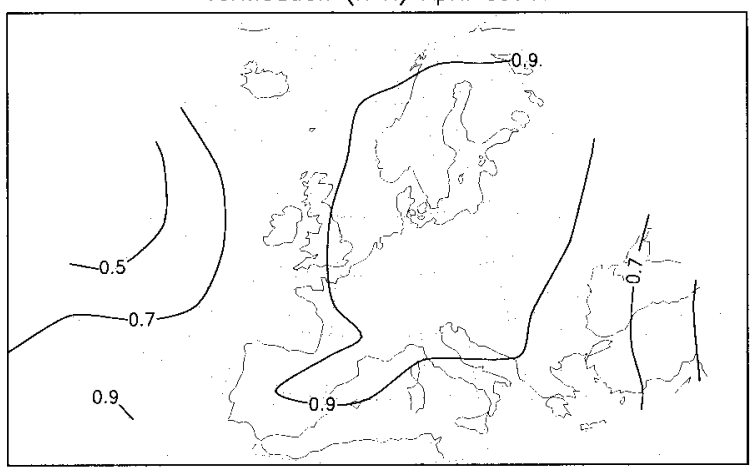

verification (R*R) April set $H$

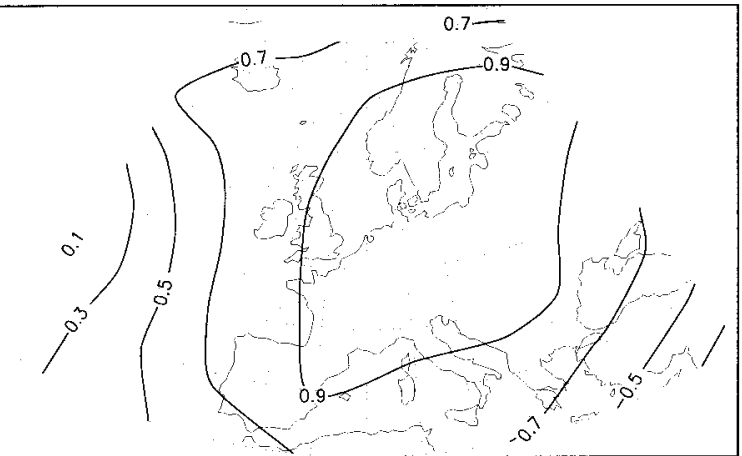

verification $(R * R)$ April set $E$

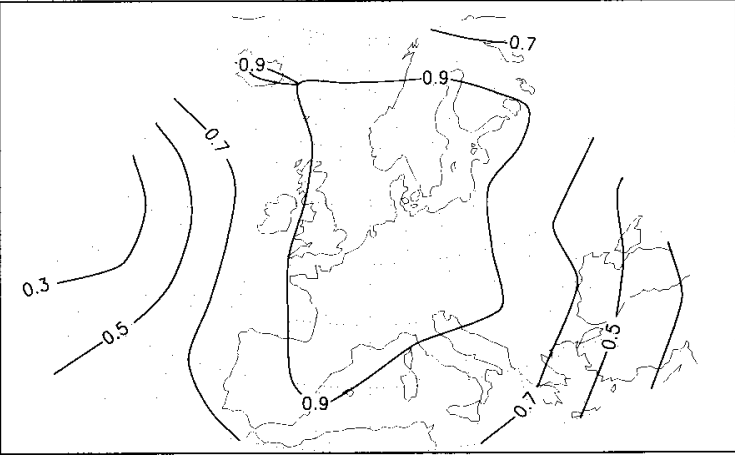

verification $(R * R)$ April set $L$

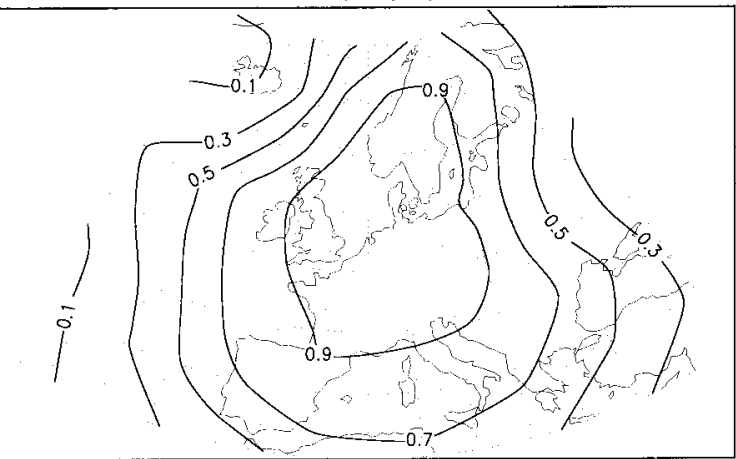

Figure 5. As Figure 4 but for April 
verification $(R * R)$ July set $A$

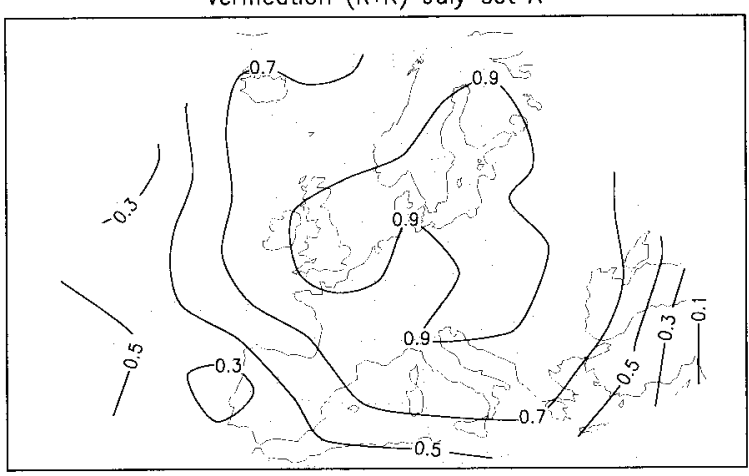

verification $(R * R)$ July set $H$

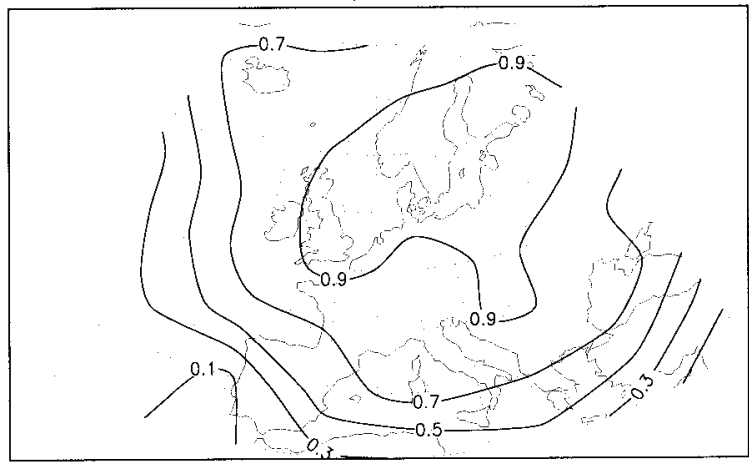

verification $(R * R)$ July set $E$

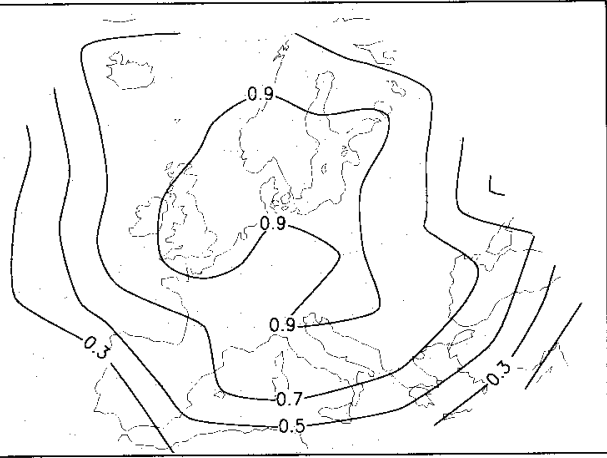

verification $(R * R)$ July set $L$

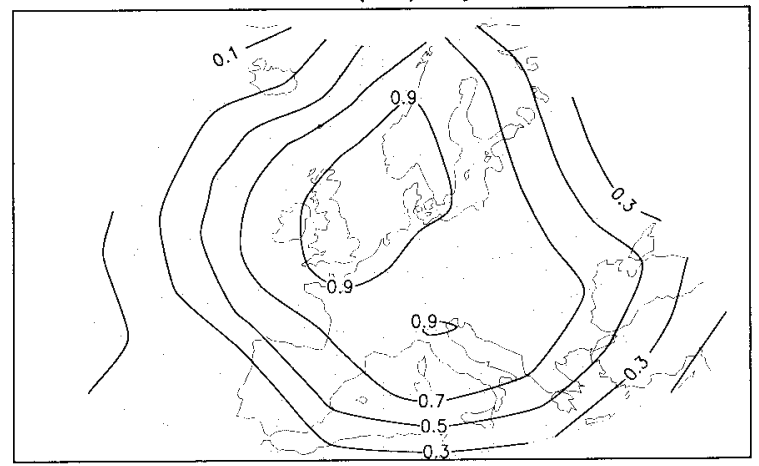

Figure 6. As Figure 4 but for July

verification (R*R) October set $A$

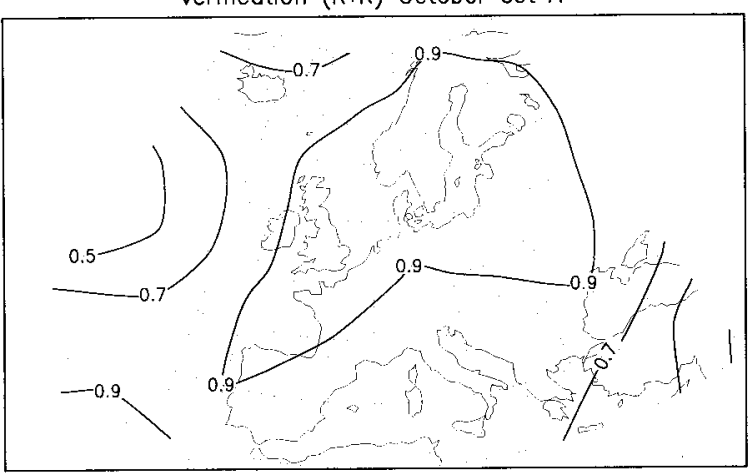

verification $(R * R)$ October set $H$

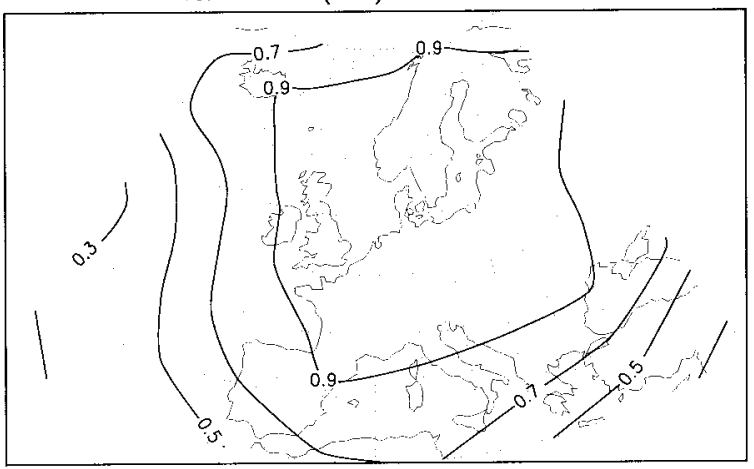

verification $(R * R)$ October set $E$

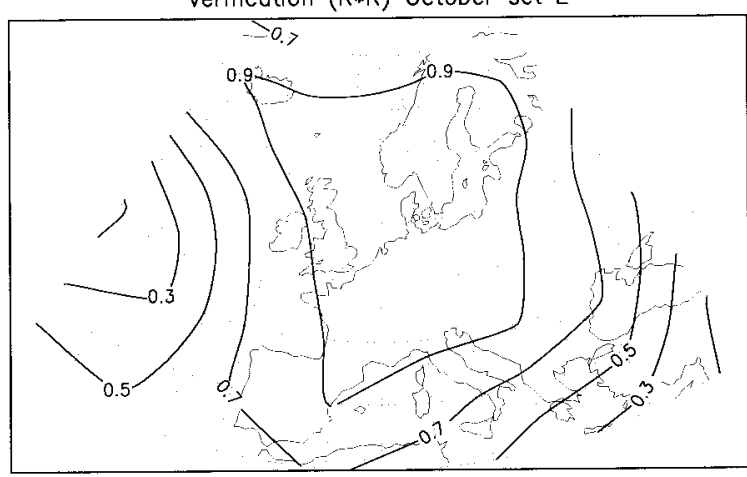

verification $(R * R)$ October set $L$

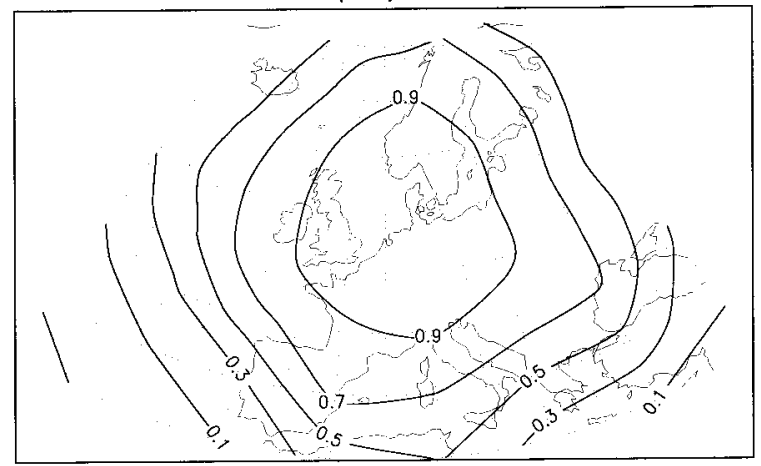

Figure 7. As Figure 4 but for October 


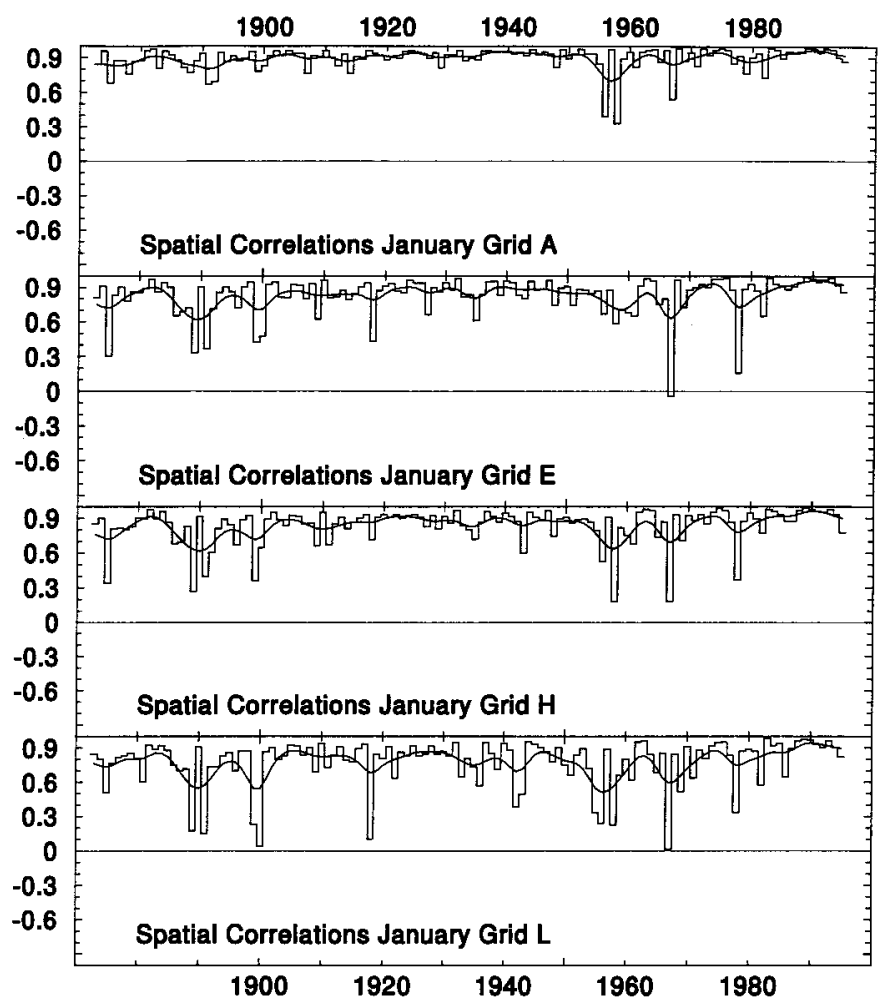

Figure 8. Time series of spatial correlations $1873-1995$ for January for networks A, E, H and L

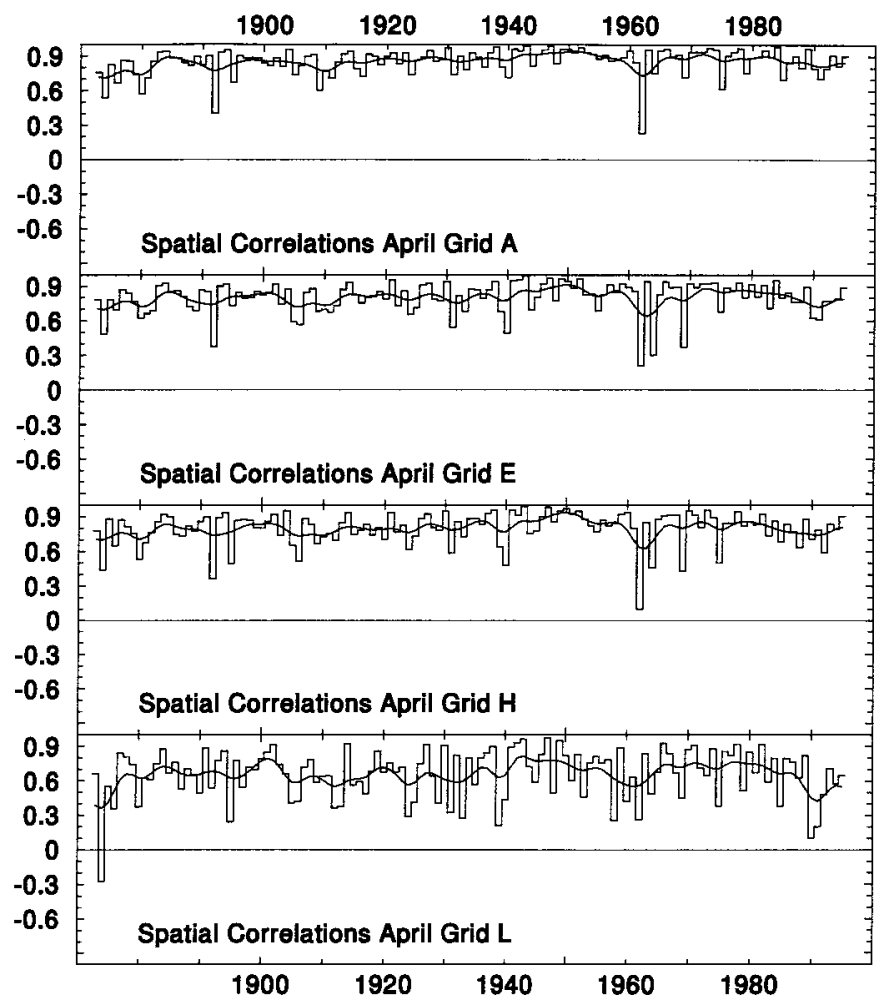

Figure 9. As Figure 8 but for April 


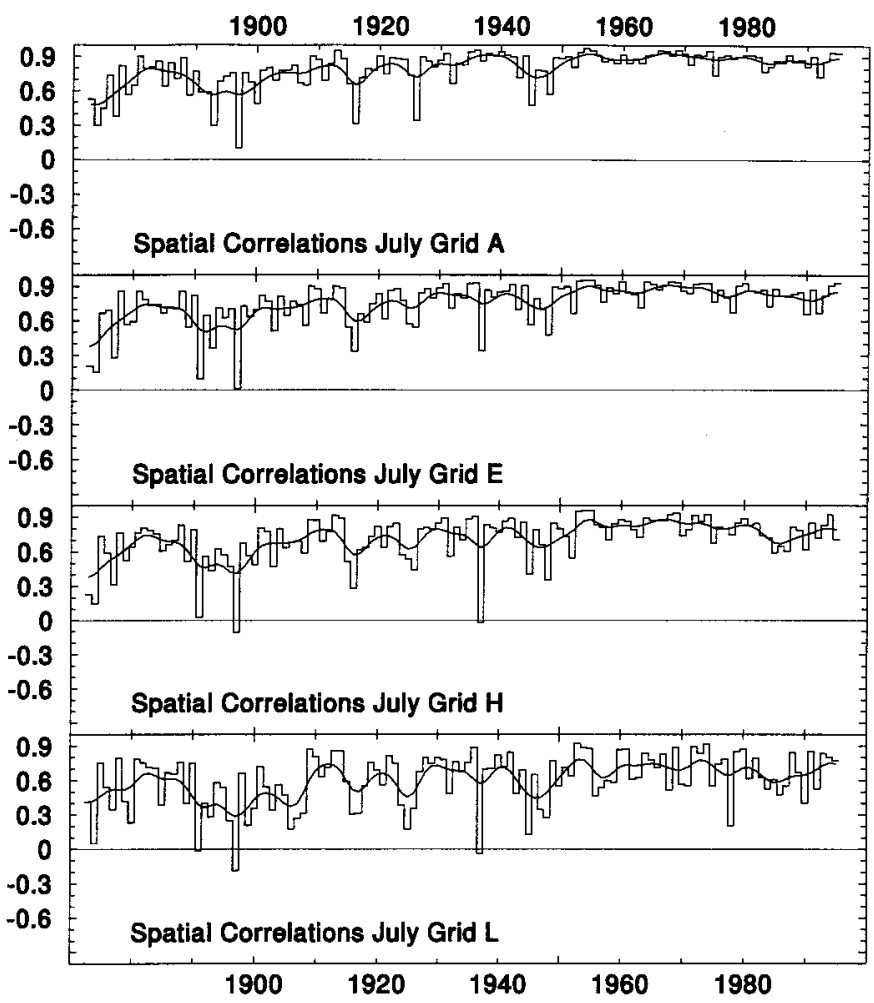

Figure 10. As Figure 8 but for July

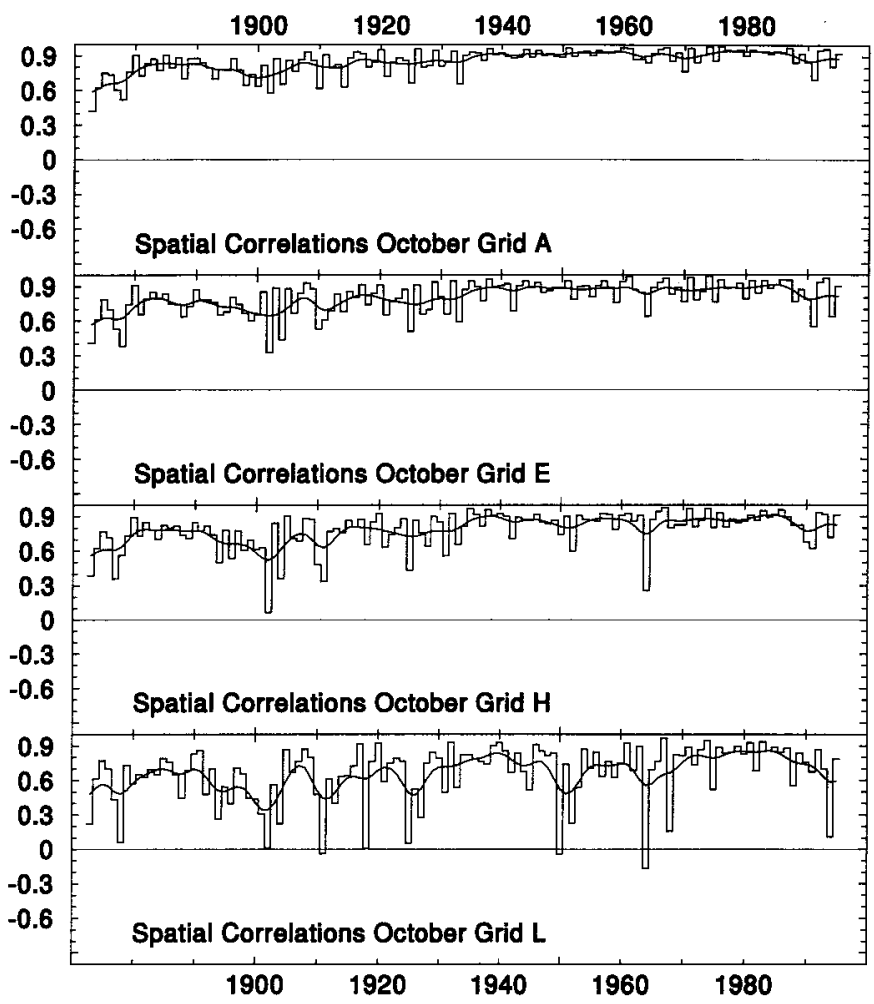

Figure 11. As Figure 8 but for October 
will be achieved, as pressure is generally high over south-western Europe (especially the Azores) and low near Iceland. To counter this effect and improve the usefulness of the analysis, both reconstructed and real data were normalised by subtracting the observed mean and dividing by the observed standard deviation, both calculated over the 1936-1995 period on a monthly basis.

Figures 8-11 show the results from January, April, July and October for networks A, E, H and L, respectively. As would be expected, those networks having a greater number of stations perform better, although this is not always the case (e.g. the late 1950s for network A in January; Figure 8). The results shown are always better over the calibration period from 1936 to 1995 compared to those from 1881 to 1935, a feature that is sometimes less apparent in Figure 3.

The apparently remarkably poor months which repeat themselves in all grids in some years can be misleading. The normalization procedure can lead to very poor results when the observed data are very close to the average (1936-1995) conditions. However, if the normalization step had not been performed and the spatial correlations calculated with actual pressure values, the whole character of these results would change. Lower mean correlations would occur in winter and higher ones in summer, a result that is clearly incorrect given the evidence in Figure 3.

\section{COMPARISONS WITH EARLIER WORK}

Although the reconstructions have been adequately verified in the previous section over the 1881-1935 period: two gridded pressure datasets can be used to assess some of the pre-1881 period: the two chart series
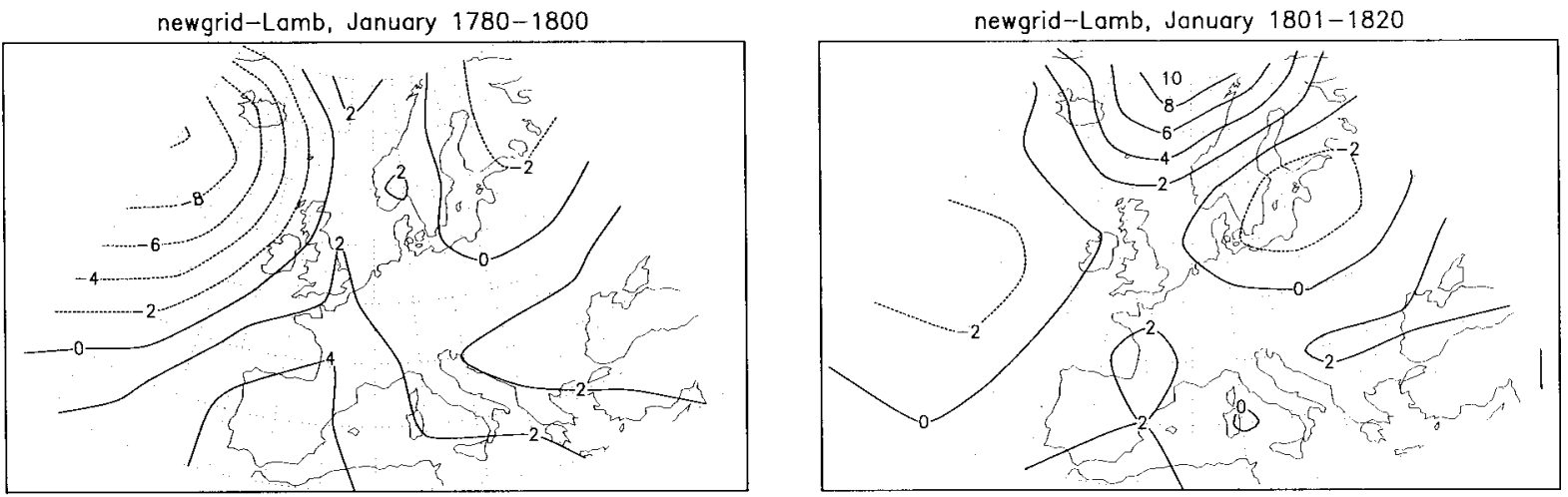

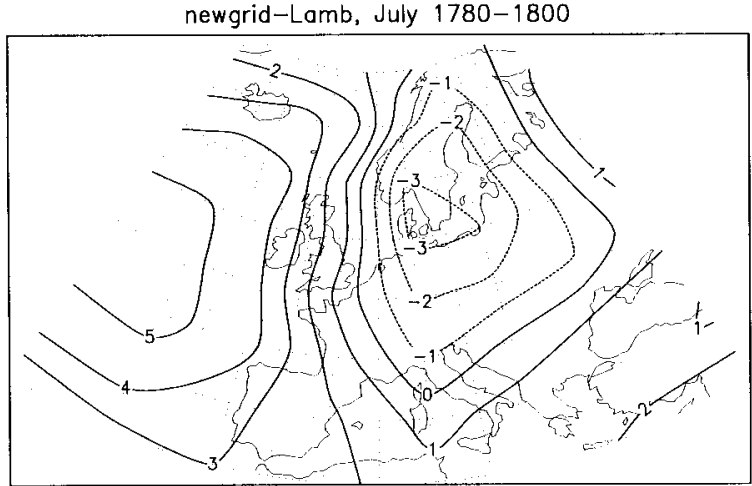

(a)

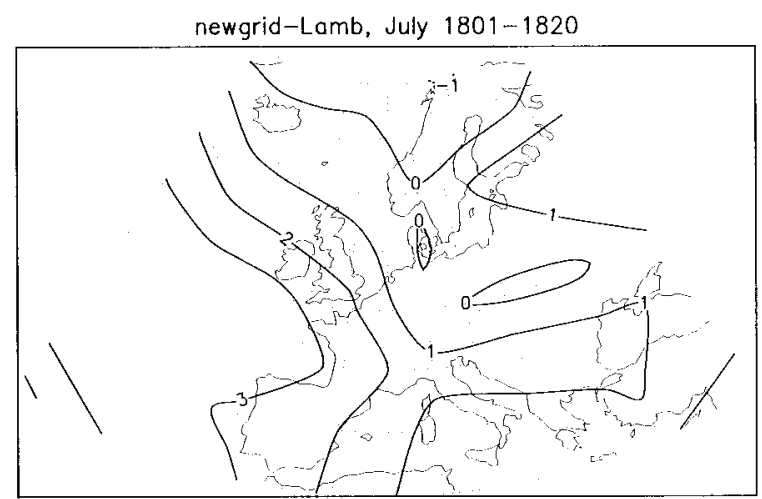

(b)

Figure 12. Anomaly pressure differences (this analysis minus Lamb and Johnson, 1966) for January and July for five periods: (a) 1780-1800; (b) 1801-1820; (c) 1821-1840; (d) 1841-1864; and (e) 1865-1880. Units are hPa 

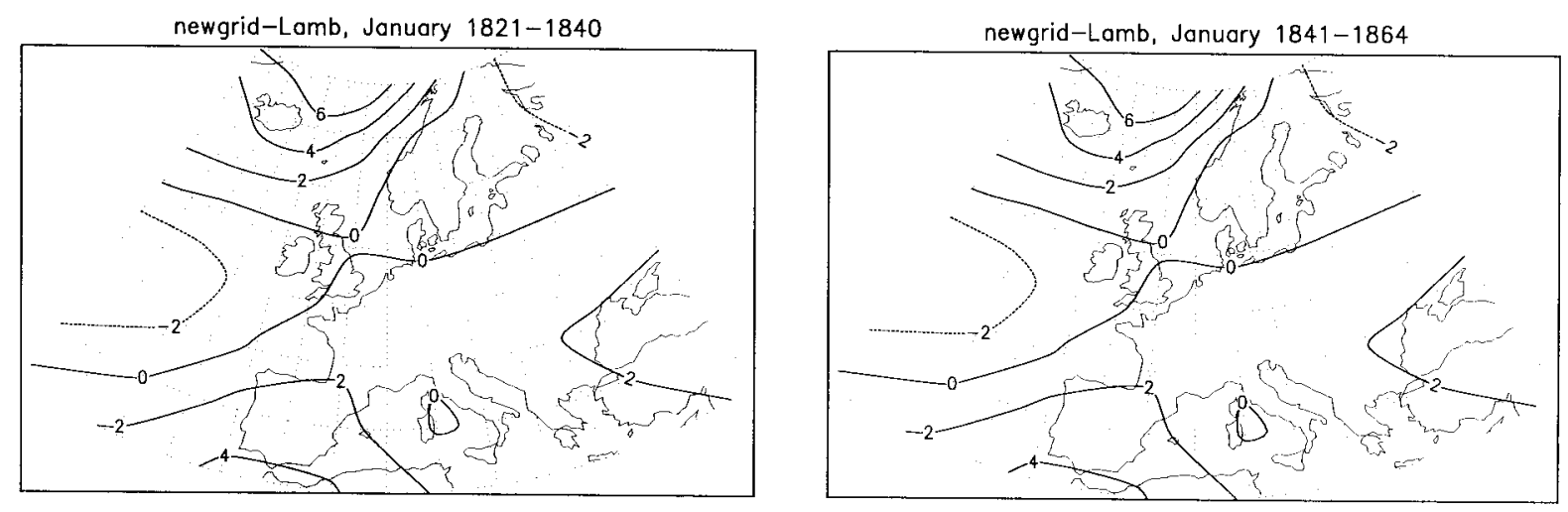

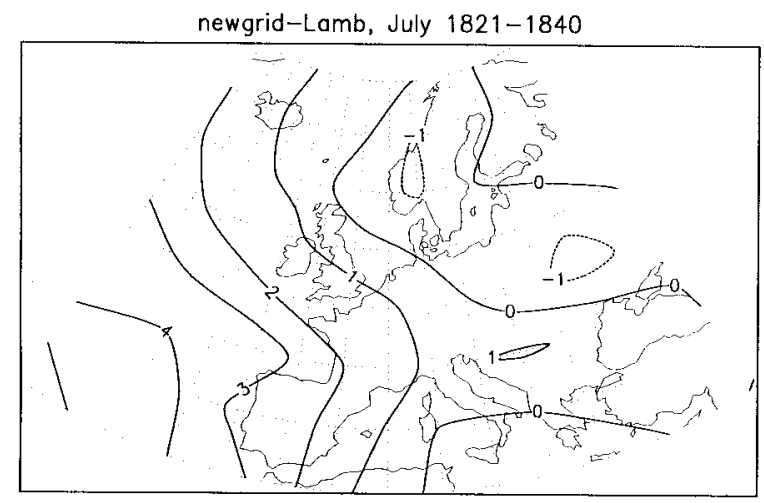

(c)

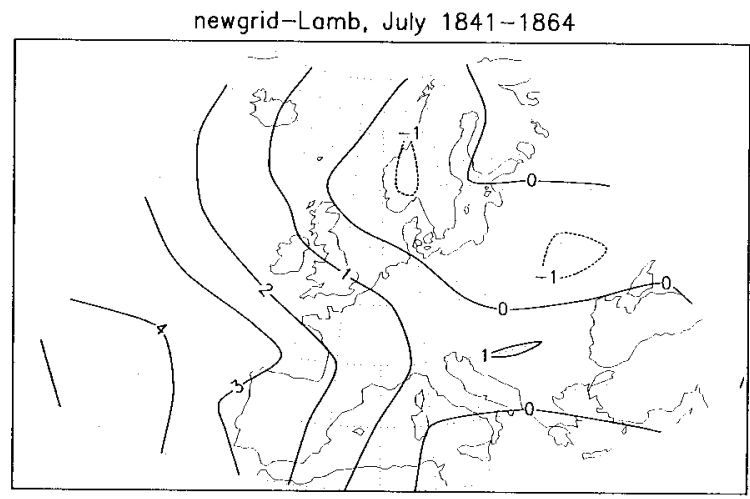

(d)

Figure 12 (Continued)

developed by Lamb and Johnson (1966) and Kington (1980, 1988) which were briefly introduced in Section 2.1. Comparisons with these early chart series can be viewed as additional verification of the reconstructions developed here, but they can equally well be viewed as assessments of the earlier chart series.

\subsection{Lamb and Johnson (1966)}

Lamb and Johnson (1966) have constructed monthly MSLP charts for the months of January and July back to 1750 by subjectively contouring MSLP data. For the earliest years, additional records from temperature, precipitation and wind data have been used together with some descriptive information from diaries. The charts become global during the present century, but for our eastern Atlantic-European region they are complete for the entire period from 1780 to 1880 . The original working charts were digitised at the UKMO in the late 1960s/early 1970s, although the published charts are believed to be of higher quality (H.H. Lamb, personal communication). Working charts exist for April and October, but were never published nor digitised. They are available for consultation at the Hadley Centre (David Parker).

We compared our reconstructions with these charts using the methods described in Sections 4.2 and 4.3. We can also directly compare the mean MSLP values between the two analyses. Since both our reconstructions and Lamb and Johnson's charts have fewer numbers of stations in the earliest years, we compared the mean pressures in Figure 12 for five periods: (a) 1780-1800; (b) 1801-1820; (c) 1821-1840; (d) 1841-1864; and (e) 1865-1880. As would be expected, as the data availability in both datasets improves during the 19th century, the pressure differences reduce, with values of $<2 \mathrm{hPa}$ for the last two 

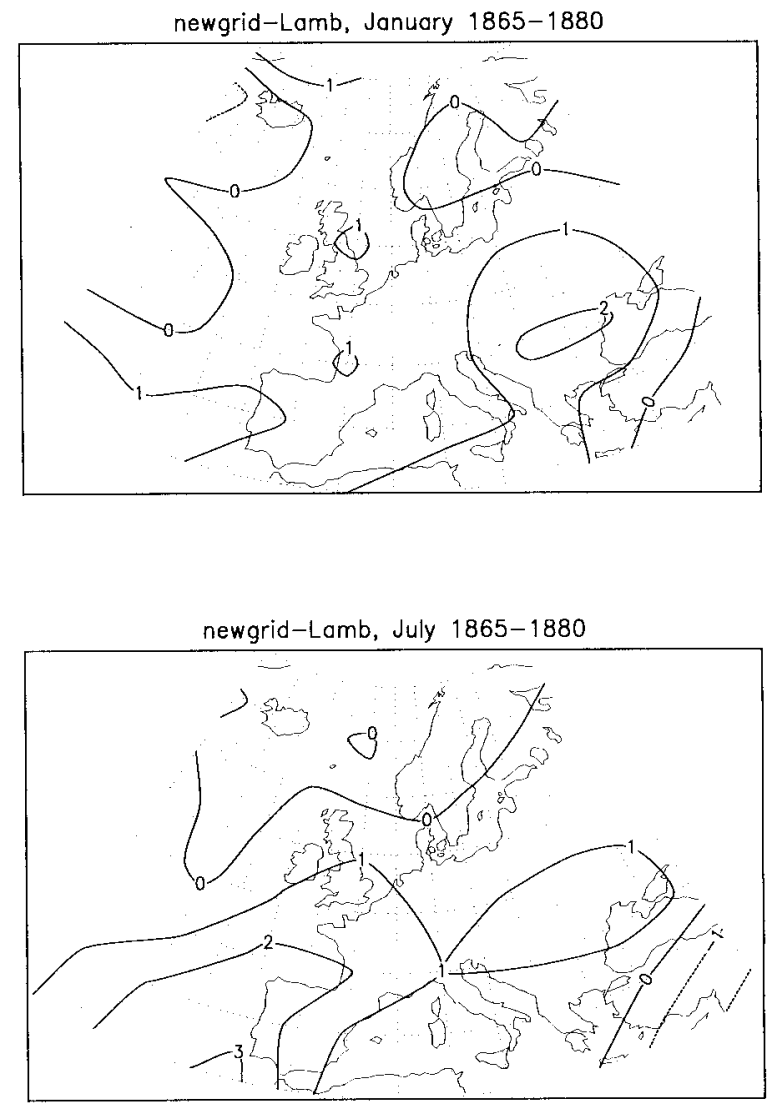

(e)

Figure 12 (Continued)

periods. The three early periods indicate larger differences, particularly for January near the periphery of the grid in the central North Atlantic. The different features change markedly from period to period in January, but for the July pressure, the Lamb and Johnson charts are consistently lower over the eastern Atlantic. Regions where values are within $\pm 1 \mathrm{hPa}$ lie over western and central Europe, as would be expected from the quality and numbers of station data.

The variance agreement between the grid-point time series is assessed in Figure 13 for January and July. The values are lower than in the equivalent figures for the verification period 1881-1935 (Figures 4 and 6 , network L). The best agreement is over the same regions as in the above figures, the implication of this being that the Lamb and Johnson (1966) charts are best where most data are available.

Spatial correlations (Section 4.3) between the two data sets are shown in Figure 14. In January, correlations are low before the mid-1810s, and for July before the early 1840s. Even for the later period, spatial correlations are lower than for the verification period 1881-1935 shown in Figures 8 and 10.

\subsection{Kington $(1980,1988)$}

Kington $(1980,1988)$ has produced daily charts for the period 1781-1786 using available instrumental data for this period which is quite extensive. Kington's charts cover the region $45-65^{\circ} \mathrm{N}, 10^{\circ} \mathrm{W}-30^{\circ} \mathrm{E}$ and have between 20 and 35 grid-points in common with our analyses. The daily charts were digitised in the early 1980s (Farmer and Wigley, 1984), monthly means being calculated for the January 1781-September 1785 (57 months) period.

The agreement between these 57 months of charts and the reconstructions is generally excellent, although the domain (central western Europe) over which comparisons are possible has been shown to be 


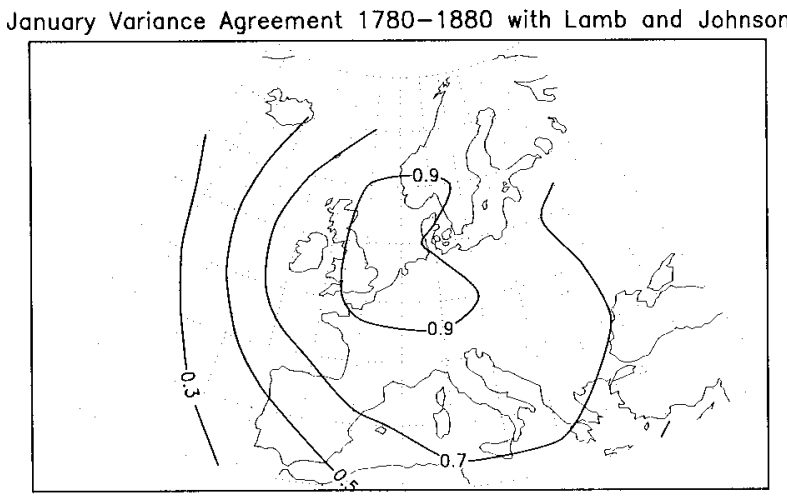

July Variance Agreement 1780-1880 with Lamb and Johnson

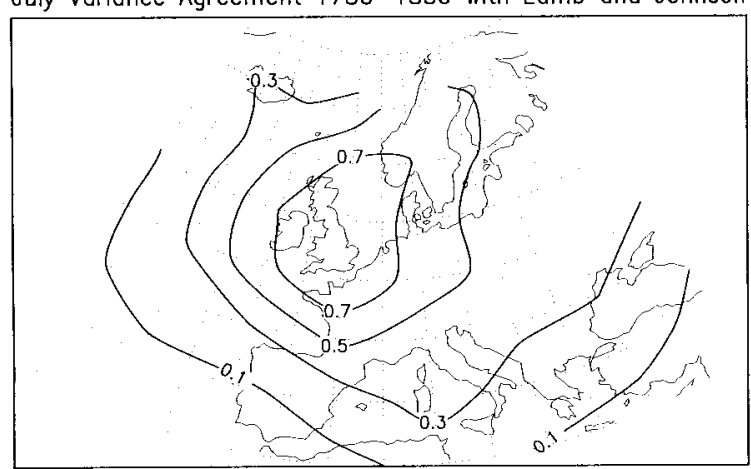

Figure 13. Variance in common between the January and July reconstructions from this analysis and those of Lamb and Johnson (1966) for the period $1780-1880$

the best in all the earlier comparisons over the verification period and with Lamb and Johnson's data. Figure 15 shows the differences between the reconstructions and the Kington charts for the four seasons using all possible monthly differences for the 57 months. Differences are always in the range $\pm 2 \mathrm{hPa}$. The variance agreement over the period (not shown) has values between 0.8 and 0.85 over the British Isles and adjacent parts of continental Europe. With the exception of a few months, the spatial correlation values are $>0.5$ (Figure 16). Again, the small domain of these comparisons should be borne in mind. Better

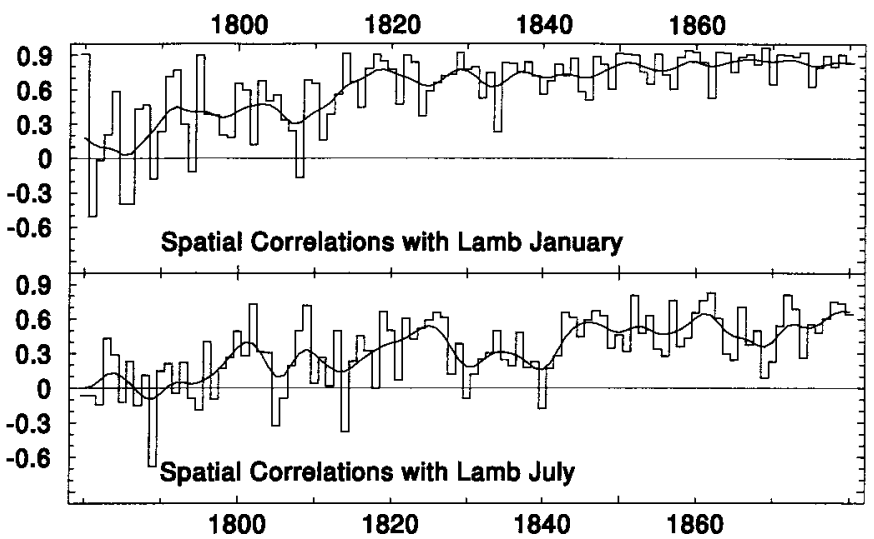

Figure 14. Time series of spatial correlations between the January and July reconstructions from this analysis and those of Lamb and Johnson (1966) for the period 1780-1880. For each year, the best network from the present reconstruction has been used 

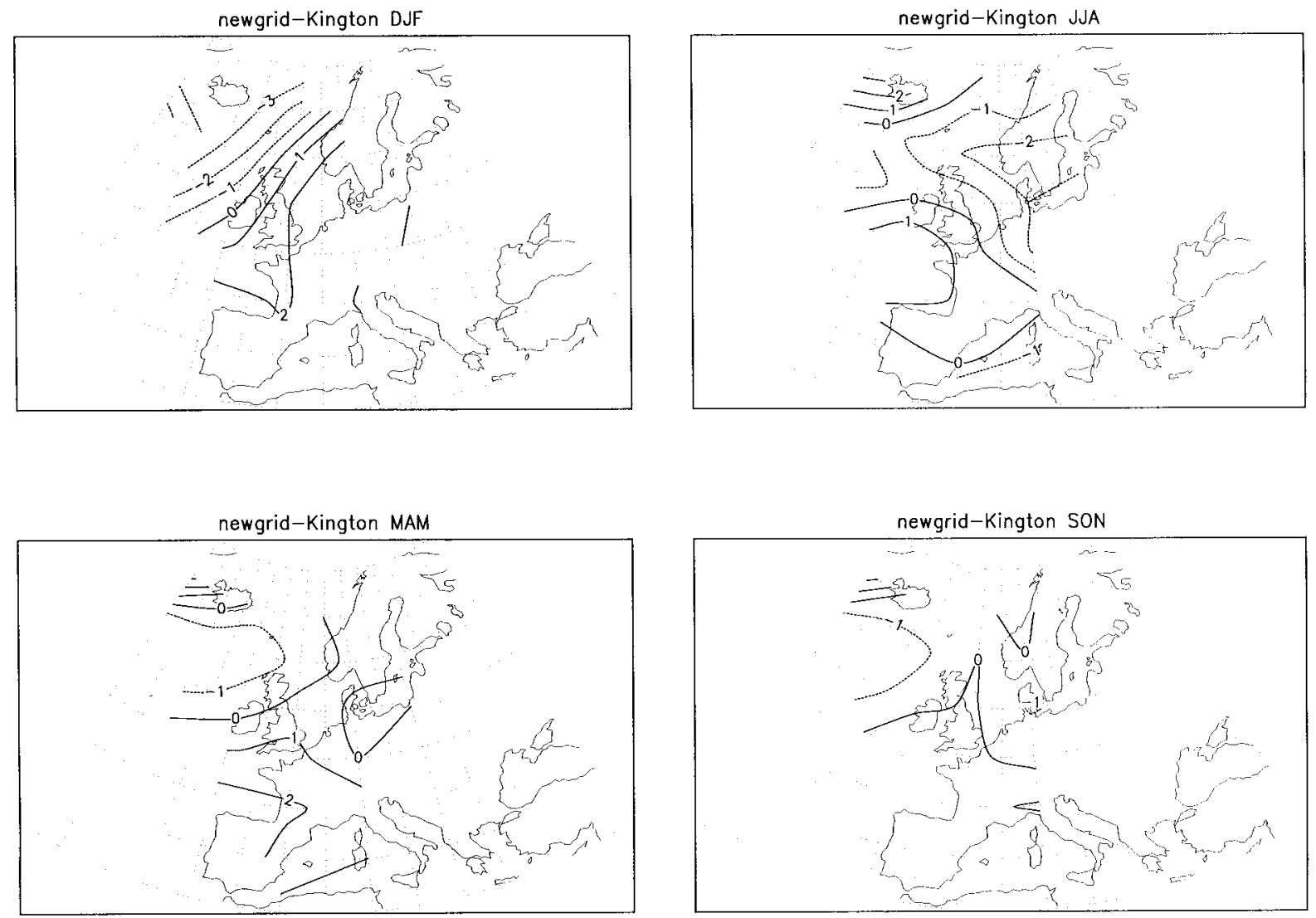

Figure 15. Seasonal pressure differences between the present reconstructions and those of Kington (1980, 1988). The 57 months, January 1781 -September 1785 were apportioned to the appropriate season

results over the verification period 1881-1935 and with the charts of Lamb and Johnson (1966) would have been achieved if a smaller central core of grid-points had also been used in these comparisons.

\subsection{Summary}

Both of the additional gridded datasets confirm the results of the verification analyses in Section 4, namely that there is a core region over which the reconstructions are excellent. This region tends to be larger during the winter than in summer months. Outside this core region, it is impossible to say whether the reconstructions or the Lamb and Johnson (1966) charts are likely to be more correct. Our reconstructions have used additional sources of information from Madrid and Barcelona and should be better in this region. Elsewhere, there are similar sources between the two datasets and the differences must be related to the potential errors in either analysis.

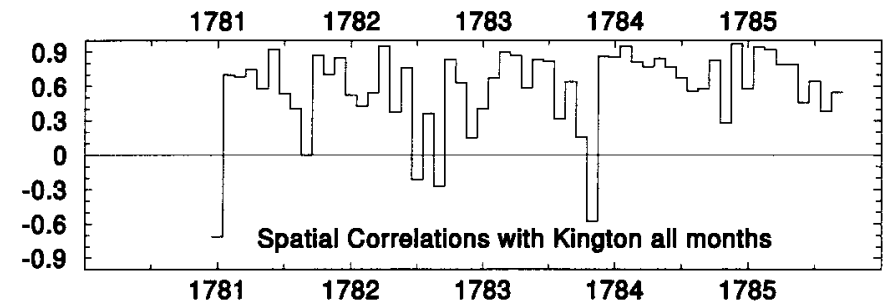

Figure 16. Time series of spatial correlations between the reconstructions from this analysis and those of Kington (1980, 1988) for the 57 months, January 1781 -September 1785. 


\section{CONCLUSIONS}

Monthly mean sea level pressure maps have been produced for the European region back to 1780 from station pressure data. To allow for the gradual improvement in the station network since then, different networks of stations have been used in a principal components regression technique, derived over a calibration period (1936-1995) and independently verified over the period from 1881 to 1935 . The quality of the reconstructions is generally excellent, with verification $r^{2}$ values exceeding 0.9 in most regions. Reconstruction quality decreases in the earliest regions around the periphery of the grid, particularly during the summer months. The greater coherency of the circulation during winter months means that the quality of the reconstructions is greater during these months.

Comparisons with other monthly pressure reconstructions produced by Lamb and Johnson (1966) since 1780 and Kington $(1980,1988)$ for 1781-1785 indicate biases and systematic differences relative to the present reconstructions. Before 1820, these differences become larger and it is difficult to say which, if either, is correct. The quality of the charts produced here has been comprehensively assessed and in many cases it is suggestive that the biases result from the other chart series.

\section{ACKNOWLEDGEMENTS}

The authors thank the staff of various libraries around Europe, in particular the National Meteorological Library at the Meteorological Office, Bracknell, UK. Tracy Basnett and David Parker helped with data availability from the Hadley Centre archives. Modern data for Milan were provided by Maurizio Maugeri and for Florence by Christian Holtz. This work is part of the ADVICE project, funded by the European Commission under contract ENV4-CT85-0129. V. Slonosky was supported by the Natural Sciences and Engineering Research Council of Canada.

\section{REFERENCES}

ADVICE. 1998. Final Report of the ADVICE (Annual to Decadal Variability in Climate in Europe) Project, 44 pp. plus 8 Appendices and 13 Annexes.

Alexandersson, H. 1986. 'A homogeneity test applied to precipitation data', J. Climatol., 6, 661-675.

Basnett, T.A. and Parker, D.E. 1997. Development of the Global Mean Sea Level Pressure Data Set GMSLP2, Climatic Research Technical Note No. 79, Hadley Centre, Meteorological Office, Bracknell, 16 pp.

Beck, C. and Jacobeit, J. 1997. 'Nordatlantisch-europeische Zirkulationsveränderungen zwischen fruehinstrumenteller Periode (1780-1860) und diesem Jahrhundert', Ann. Meteorol., 34, 63-64.

Briffa, K.R., Jones, P.D., Wigley, T.M.L., Pilcher, J.R. and Baillie, M.G.L. 1986. 'Climate reconstruction from tree rings Part 2. Spatial reconstruction of summer mean sea-level pressure patterns over Great Britain', J. Climatol., 6, 1-15.

Cook, E.R., Briffa, K.R. and Jones, P.D. 1994. 'Spatial regression methods in dendroclimatology - a review and comparison of two techniques', Int. J. Climatol., 14, 379-402.

Farmer, G. and Wigley, T.M.L. 1984. The reconstruction of European Climate on Decadal and Shorter Time Scales, Final Report to the Commission of European Communities, Contract No. CL-029-81-UK(H), 380 pp.

Hann, J. 1887. Die Vertheilung des Luftdruckes über Mittel und Süd-Europa, Eduard Hölzel, Wien.

Gorczynski, W. 1917. Pression Atmosphérique en Pologne et en Europe, Warsaw (in Polish and French), 265 pp.

Jones, P.D. 1987. 'The early twentieth century Arctic high-fact or fiction?', Clim. Dyn., 1, 63-75.

Jones, P.D., Wigley, T.M.L. and Briffa, K.R. 1987. Monthly Mean Pressure Reconstructions for Europe (back to 1780) and North America (to 1858). Technical Note TR037, U.S. Dept. of Energy, Washington D.C., 99 pp.

Kington, J.A. 1980. 'Daily weather mapping from 1781', Clim. Change, 3, 7-36.

Kington, J.A. 1988. The Weather of the 1780s over Europe, Cambridge University Press, Cambridge, 166 pp.

Lamb, H.H. and Johnson, A.I. 1966. Secular variations of the atmospheric circulation since 1750. Geophys. Mem. 110, London (HMSO for Met. Office), $125 \mathrm{pp}$.

Preisendorfer, R.W., Zwiers, F.W. and Barnett, T.P. 1981. Foundations of Principal Component Selection Rules, SIO Ref Series 81-4, Scripps Institution of Oceanography, La Jolla, California, $192 \mathrm{pp}$.

de Tillo, A. 1890. Reparition géographique de la pression atmosphérique sur le territoire de L'Empire de Russie, 1836-85, La Societé Imperiale Russie de Géographie, St. Petersburg.

Trenberth, K.A. and Paolino, D.A. 1980. 'The Northern Hemisphere sea-level pressure data set: trends, errors and discontinuities', Month. Weather Rev., 108, 855-872.

Williams, J. and van Loon, H., 1976. 'An examination of the Northern Hemisphere sea-level pressure data set', Month. Weather Rev., 104, 1354-1361. 